\title{
Cultura popular y letrada en Vlad, novela neogótica de Carlos Fuentes
}

\author{
DANIRA LÓPEz TORRES*
}

Resumen:

El presente comentario pretende mostrar el funcionamiento del cronotopo de la novela gótica en "Vlad" (2004), de Carlos Fuentes, y subrayar la función que cumple la incorporación del folklore en el género gótico, al permitir que antiguos relatos cobren vida en el siglo xxi, un espacio-tiempo distinto al original. Lo anterior se logra en esta novela breve mediante la incorporación de tres principales elementos en el relato: el personaje mítico del vampiro, el espacio del castillo y la representación del acto de transmisión y rememoración de esas historias, legendarias y fantasmagóricas, del pasado.

\section{Palabras clave:}

Vampiro, cronotopo, novela gótica, folklore.

Si el sueño de la razón produce monstruos [...] el vampiro es el más prestigiado, temido y admirado [...] semejante omnipotencia se halla en que [...] al separarse del mundo de los vivos, el vampiro conserva las características de los humanos, pero además consuma los deseos que nosotros, en nuestra limitada condición, apenas nos atrevemos a nombrar.

(Vicente Quirarte, “Presentación” de Drácula)

* El Colegio de San Luis. 
En 2010, año del centenario y bicentenario de las revoluciones en México, Carlos Fuentes publica Vlad, novela breve (nouvelle o novelette) que presenta una nueva versión de un antiguo y conocido monstruo, el vampiro. En este caso, usando como principal hipotexto el clásico de Bram Stoker, Drácula (1897). Si bien el texto de Fuentes privilegia los referentes europeos del mito, existe en la tradición literaria hispanoamericana una presencia del vampiro, desde el siglo XIX hasta nuestros días, aunque poco atendida. Algunos ejemplos rastreados por la crítica ${ }^{1}$ son: "La viuda de Corinto" (1837), del venezolano Fermín Toro; “Gaspar Blondín” (1858), del ecuatoriano Juan Montalvo; y "El beso del espectro" (1891), del venezolano Luis López Méndez; en el siglo xx la nómina crece e incluye autores consagrados como Leopoldo Lugones con "El hombre muerto" (1907); Clemente Palma, "Las vampiras" (1904); Rubén Darío, “Thanotopia” (1893); Horacio Quiroga, "El vampiro" (1927); Julio Cortázar, "El hijo del vampiro" (1937) y "Reunión del círculo rojo" (1977); Salvador Garmendia, "Claves" (1979); Severo Sarduy, "Vampiros reflejados en un espejo convexo" (1986); Carlos Fuentes, "Vlad" (2004), Mauricio Molina, "La máscara del Dios vampiro” (2006) y César Silva Márquez, Los cuervos (2006), entre otros títulos.

Como refiere Ricardo Gutiérrez Mouat: "El género literario que convencionalmente aloja al monstruo es el gótico, género que en la narrativa latinoamericana ha sido prácticamente ignorado por la crítica” (5). El estudioso afirma que el más gótico de los escritores latinoamericanos de la modernidad es precisamente Carlos Fuentes, pues su obra abre y concluye con relatos de este género: el "Chac Mool” (1954) y Vlad (Gutiérrez 6). Además de los textos referidos, Fuentes cuenta con muchas otras narraciones que podrían considerarse góticas entre las que destacan: Los días enmascarados (1954), Aura (1962), Cumpleaños (1969), Una familia lejana (1980),

${ }^{1}$ Ver la revisión elaborada por Alicia Nila Martínez Díaz, "Cortázar, Fuentes y Molina en los confines de lo humano: tres cuentos de vampiros", Anales de Literatura Hispanoamericana, vol. 45, 2016, pp. 429-448. 
Constancia y otras novelas para vírgenes (1989), Instinto de Inez (2001) y Carolina Grau (2010); así como, por supuesto, muchas de las obras compiladas bajo el título "El mal del tiempo".

En cuanto a los referentes aludidos por Fuentes, la historia narrada en "Vlad" sigue muy de cerca las pautas generales de la novela de Stoker -sobre todo al inicio- y poco a poco incorpora diversos elementos que configuran una versión particular del vampiro que da un giro inesperado al desenlace de la historia. El nombre del conde Vlad, elegido por Fuentes, alude al príncipe rumano del siglo XV, Vlad III Draculea (hijo de Vlad in Dracul), mejor conocido como Vlad "Tepes", "el Empalador", por su crueldad para torturar y asesinar. Ralf-Peter Märtin destaca, en su estudio Drácula. Vlad Tepes, el Empalador, y sus antepasados, la genialidad de Stoker al construir al monstruo:

Stoker obra de un modo trascendental en la organización de los elementos de que dispone. Necesita una región lo bastante remota como para afincar un mito, y encontró Transilvania [...] De los grupos étnicos que allí viven, rumanos, húngaros, szekler y alemanes, los szekler se distinguen precisamente por su origen secreto, sospechándose que descienden de los hunos $[. .$.$] en vano se buscaría al conde Drácula en sus anales;$ los voivodas que llevaron ese nombre eran dos príncipes rumanos del siglo xv, Vlad II Dracul, y Vlad III «Tepes» [...] De las fuentes que estaban a su disposición pudo deducir que Vlad se caracterizaba [...] por su afición a salvajes orgías de ejecución [...] empalaba a sus víctimas para después almorzar entre ellas; de ahí su apodo Tepes, «empalador». Stoker interpretó de modo vampirista tanto esta crueldad morbosa [...] como el hecho de que a los príncipes rumanos del siglo XV rara vez se les concediera una muerte apacible. Tanto Vlad II como su hijo alcanzaron el fin de sus vidas prematuramente, la idea del regreso, de la vida incompleta que deseaba ser vivida hasta el final, era inherente a los dos, y el Drácula de Stoker aparece en realidad como la consecuente imposición de un pensamiento lógico y estratégico (Märtin 12-13). 
Con este puñado de elementos esenciales, Stoker funda su mito; retoma el apellido del personaje histórico que dará fama al vampiro Drácula y, a su vez, Fuentes recurre al referente historiográfico y toma no el apellido sino el nombre del personaje para configurar, en torno a éste, su muy particular versión del monstruo, a quien denomina conde Vladimir Radu; "Vlad, para los amigos", especifica el vampiro al protagonista de la novela, con un lenguaje y actitud aparentemente amigables que deslizan, de entrada, un tonillo irónico y perverso; pues para Vlad, los "amigos", aquellos con quienes establece algún tipo de relación, son siempre sus víctimas.

"Vlad" se publica primero como parte del libro de relatos Inquieta compañia (2004) -compuesto, en este orden, por "El amante del teatro", "La gata de mi madre", "La buena compañía", "Calixta Brand", "La bella durmiente" y concluye con "Vlad"-, de donde la crítica reiteradamente lo destaca por el referente conocido del que parte -que propicia el comentario casi obligado-y por ser el texto de mayor extensión del libro. Ese mismo año, Mauricio Molina diferencia los relatos que componen la publicación: "Inquieta compañia de Carlos Fuentes es un libro compuesto por cinco relatos y una novela corta" (Molina 33), además advierte que, por ser "Vlad" el texto más extenso del libro, "por sí mismo merecería una edición aparte, es sin lugar a dudas el más imaginativo y, al mismo tiempo, el más personal de la colección” (Molina 35). En relación con esta última afirmación, Molina plantea la hipótesis de la presencia de un filón autobiográfico en "Vlad":

Vlad Tepes, modelo de todos los vampiros, aparece aquí para combinarse con la realidad personal y biográfica. De ahí que haya que irse con cuidado en la lectura del texto. [...] aparece aquí un elemento perturbador: la muerte del hijo de la pareja protagonista y la voluntad de regresarlo de la tumba. Este solo elemento convierte a "Vlad" en uno de los textos más personales de Carlos Fuentes. Más allá de la escenografía arquetípica, se esconde el dolor de la pérdida, la disolución de la psique en imágenes que apuntan hacia la pregunta acerca de la muerte. La transfiguración del dolor en la literatura no 
es tan sólo un arte catártico, lo cual sería meramente anecdótico, sino una suerte de acto mágico, demiúrgico, ritual. No se puede comprender este tipo de literatura sin un trasfondo donde relumbran al mismo tiempo el dolor y lo sagrado (Molina 35-36).

Dicha hipótesis cobra relevancia al final del relato al dar un giro inesperado al desenlace de la historia, momento en que adquiere sentido el elemento autobiográfico observado por Molina. El relato "Vlad" atrae rápidamente la atención de los lectores y, como había sugerido Molina, en junio de 2010 se publica la primera edición de la novela $\mathrm{Vlad}^{2}$ como texto autónomo. Dicha publicación se produce en medio de una gran difusión que involucró su presentación en el marco de la Feria Internacional del libro (FIL) de Guadalajara - celebrada en noviembre de ese mismo año-, nada menos que por el escritor y director de cine Guillermo del Toro, experto conocedor del género. ${ }^{3}$ Después de la transmisión de una cápsula en video, mediante la que Carlos Fuentes se hace presente para narrar un fragmento de su novela al público asistente a la presentación, ${ }^{4} \mathrm{Del}$ Toro expone su comentario sobre Vlad: "es una pieza clave en la literatura fantástica en español [...] y una de las novelas más perturbadoras de vampiros que he leído". ${ }^{5}$ Uno de los elementos que

${ }^{2}$ De su primera aparición en el libro Inquieta compañia (2004) a esta segunda, como texto autónomo, el relato no sufre ningún cambio. En su publicación independiente Vlad (2010) alcanza una extensión de ciento once páginas, casi el doble de la amplitud de Aura (1962), que se compone de alrededor de sesenta páginas.

${ }^{3}$ En esa misma ocasión, Guillermo del Toro presenta en la FIL su última novela, la segunda de su Trilogía de la oscuridad, compuesta por las historias de vampiros Nocturna (2009), Oscura (2010) y Eterna (2011).

${ }^{4}$ Carlos Fuentes presenta un fragmento de su novela Vlad, que puede consultarse en https://www.youtube.com/watch?v=D2-v9niw0Ko, y una entrevista al autor sobre esta novela puede encontrarse en https://www.youtube.com/watch?v=fDexiTeL-3w (ambas consultadas el 4 de septiembre de 2017).

${ }^{5}$ El comentario de Guillermo del Toro sobre la novela Vlad puede consultarse en un fragmento de la presentación del libro localizado en: https://www. youtube.com/watch?v=dg7N5CFjfBw (consultado el 4 de septiembre de 2017). 
llama la atención de Del Toro es la variada utilización de fuentes eruditas por parte del autor:

de manera muy docta [...] utiliza fuentes, tanto fílmicas como literarias, profundamente variadas, pero de manera, repito, erudita [...] Empieza citando a un poeta romántico, [Williams] Wordsworth, ${ }^{6}$ y queda claro que está tratando de hacer un neogótico en la Ciudad de México. El lenguaje se mantiene profundamente coloquial en la novela, lo cual es muy refrescante. Pero tiene citas, por ejemplo, a [Joseph Thomas Sheridan] Le Fanu, [Henry] James...

Molina subraya, a su vez, algunas de estas correlaciones entre las que destaca Swedenborg, Sheridan Le Fanu, Arthur Machen y Julio Cortázar (Molina 30). En la construcción que Fuentes elabora del vampiro, si bien se aprecian referencias provenientes de una cultura erudita que abreva de diversas fuentes - historiográficas, biográficas, literarias (novela y poesía), films, ${ }^{8}$ etc.-, igual peso, si no

${ }^{6}$ Carlos Fuentes alude a los siguientes versos del poema "The Prelude", del Libro Sexto, "Cambridge and the Alps", de Williams Wordsworth: "A dreary mansión, large beyond all need..." (Fuentes 16), que pone en boca del personaje Eloy Zurinaga y que refiere, precisamente, al espacio de la "mansión lúgubre" en el que habita este personaje -al igual que el conde Vlad-y que es característico de la novela gótica.

${ }^{7}$ Sheridan Le Fanu es autora de la novela breve Camille (1872), novela gótica que influyó a muchas de las historias que se publicaron posteriormente como el clásico de Bram Stoker, Drácula (1897). En cuanto a la referencia a Henry James, se refiere específicamente a su novela Los papeles de Aspern (1888). El comentario de Guillermo del Toro se encuentra en un fragmento de la presentación de la novela en: https://www.youtube.com/watch?v=a7o6Ds4akXY (consultado el 4 de septiembre de 2017).

${ }^{8}$ Entre las más destacadas se encuentran la película muda del cine alemán Nosferatu, el vampiro (1922), de Friedrich Wilhelm (seudónimo de F.W. Plumpe); la versión norteamericana Drácula (1930), de Ted Browning, con Bela Lugosi representando al vampiro; Drácula (1958) y Drácula, Príncipe de las tinieblas (1965), de Terence Fisher; Drácula vuelve de la tumba (1968), de Freddie Francis; Nosferatu, fantasma de la noche (1979), de Werner Herzog y Klaus Kinski; Drácula (1979), de 
es que mayor, otorga el autor a las correspondencias provenientes del folklore -leyendas sobre vampiros y aparecidos, conjuros para combatir a estos seres, cancioncillas y juegos infantiles de la tradición oral, entre otras-, de la misma manera que sucede en el Drácula, de Stoker, principal referente de la novela. Sin embargo, como identifica Del Toro y Molina, asoman muchos otros textos que aluden a esta literatura de autor de la que abreva Fuentes para la construcción de su propia versión del monstruo. Lo que resta por identificar es la presencia de esos otros textos provenientes del folklore literario, de los que también se alimenta el autor para lograr que esta nueva construcción del vampiro cobre vida en la mansión de la Ciudad de México, en pleno siglo xxi.

En este sentido, el presente comentario pretende mostrar el funcionamiento del cronotopo de la novela gótica en Vlad y subrayar la función que cumple la incorporación del folklore en el género gótico o neogótico, en que se inscribe el texto, al hacer posible -mediante la incorporación del personaje mítico del vampiro, el espacio del castillo y la representación del acto de transmisión y rememoración de esas historias del pasado, legendarias y fantasmagóricasque antiguos relatos cobren nuevamente vida en un espacio-tiempo diametralmente distinto al original, poblando poco a poco el escenario de esas antiguas criaturas e historias.

John Badhams, y más recientemente, la conocida cinta Drácula (1992), de Francis Ford Coppola. Con un tono paródico y satírico entran los films El baile de los vampiros (1966), de Roman Polansky y Amor al primer mordisco (1979), de Stan Dragoti. Carlos Fuentes parece poner especial atención en las historias donde aparecen niñas vampiros, pues en su interpretación adquieren relevancia, aunque no protagonismo; una de las cintas que presenta esta característica, filmada en la última década del siglo xx, es Entrevista con el vampiro (1994), del director Neil Jordan, con guion de la popular autora Anne Rice e interpretaciones de Brad Pitt, Christian Slater, Tom Cruice, Antonio Banderas y, como la niña vampiro, Kirsten Dunst. 


\section{El cronotopo de la novela gótica}

En el origen del género de la novela gótica, la crítica ha situado a Horatio Walpole con The Castle of Otranto (1764), ${ }^{9}$ texto que marca algunas de las primeras y principales características que distinguen a esta narrativa como son, por ejemplo: la presencia de un antiguo castillo tenebroso de inmensas dimensiones, pasillos en penumbra, sótanos completamente oscuros, cuadros y tapices que se estremecen, túneles sombríos, entre otras particularidades. Al respecto, $\mathrm{Fe}$ derico Patán sintetiza algunos de sus rasgos principales y menciona que es justo Walpole quien establece el neogótico:

paisajes desolados, castillos o casonas aisladas, en ocasiones bosques intransitables casi y oscuros siempre, corredores tenebrosos, celdas de negrura infinita. Pero esto, concedámoslo, es la presencia externa [...] Oculta por ese aparato físico se encuentra la intención social, cuyo basamento son las turbulencias psicológicas, las conductas ajenas a lo cotidiano, los grandes trechos de desolación existencial (122).

Un elemento particularmente importante que menciona Patán es el hecho de que la literatura gótica mantiene una estrecha relación con el terror, penetra en el alma y explora las cuestiones éticas, religiosas y morales de una sociedad. Características, todas estas, que es posible reconocer, no sin horror, en esta nueva versión del vampiro propuesta por Fuentes, ya que su criatura se muestra implacable cuando se trata de destruir los valores ético-morales del protagonista y su familia. El vampiro termina penetrando no solo en la psicología de los personajes sino corrompiendo sus valores e ideas más arraigados y desatando sus pasiones y alterando sus sueños, como se verá más adelante.

${ }^{9}$ Aunque David Roas afirma, en "Breve historia de la literatura fantástica (siglo xviii y xix)", que pocos años antes se habían publicado al menos "dos novelas clasificables como góticas: Fernando, conde de Fathom, de Tomás Smollet (1753), y Longsword, Earl of Salisbury (1762), de Thomas Leland" (65). 
Para el estudio y comprensión de la novela gótica resultan pertinentes las reflexiones expuestas por Mijaíl Bajtín, en Teoría y estética de la novela (1989), donde considera las coordenadas espacial y temporal como elementos narratológicos que integran, lo que el teórico denomina, el cronotopo: ${ }^{10}$

En el cronotopo artístico literario tiene lugar la unión de los elementos espaciales y temporales en un todo inteligible y concreto. El tiempo se condensa aquí, se comprime, se convierte en visible desde el punto de vista artístico; y el espacio, a su vez, se intensifica, penetra en el movimiento del tiempo, del argumento, de la historia. Los elementos del tiempo se revelan en el espacio, y el espacio es entendido y medido a través del tiempo. La interacción de las series y uniones de esos elementos constituye la característica del cronotopo artístico (237-238).

A partir de esta fuerte dependencia de la unidad que integran los elementos espacial y temporal, Bajtín delimita las fronteras entre los géneros y, a su vez, vislumbra el nacimiento de nuevos subgéneros al afirmar que tanto el género como sus variantes se determinan por el cronotopo (238). Es justamente la conexión entre coordenadas espaciales y temporales específicas la que posibilita la reflexión e identificación del género de la novela gótica, que nace concretamente de la unión de un nuevo espacio, el castillo, y el tiempo del pasado histórico que este espacio involucra. Al respecto, cito en extenso a Bajtín, quien afirma:

Hacia finales del siglo xvIII, en Inglaterra, se establece y se impone en la llamada «novela gótica» o «negra», un nuevo

${ }^{10}$ Bajtín refiere como "cronotopo (lo que en la traducción literal significa «tiempo-espacio») a la conexión esencial de relaciones temporales y espaciales asimiladas artísticamente en la literatura [...] [que] expresa el carácter indisoluble del espacio y el tiempo [...]. Entendemos el cronotopo como una categoría de la forma y el contenido en la literatura" (237). 
territorio de desarrollo de los acontecimientos novelescos: «el castillo» (por primera vez, en este sentido, en El castillo de Otranto, de Horacio Walpole; luego, en Radcliffe, Lewie, etc.). El castillo está impregnado de tiempo, de tiempo histórico en el sentido de la palabra, es decir, de tiempo del pasado histórico. El castillo es el lugar en que viven los señores feudales (por lo tanto, las figuras históricas del pasado); ${ }^{11}$ los siglos y las generaciones han dejado importantes huellas en diversas partes del edificio, en el ambiente, en las armas, en la galería de retratos de los antepasados, en los archivos familiares, en las específicas relaciones humanas en la sucesión dinástica, de trasmisión de los derechos hereditarios. Finalmente las leyendas y tradiciones hacen revivir, con los recuerdos de los pasados acontecimientos, todos los rincones del castillo y de sus alrededores. Esto crea una temática específica del castillo, desarrollada en las novelas góticas (Bajtín 396).

Justamente los motivos del espacio del castillo y del tiempo del pasado histórico, identificados por Bajtín, son los que permiten reconocer el subgénero e integran lo que el teórico denomina el cronotopo de la novela gótica. Uno de los principales elementos que permiten vincular a V lad con este género es el desarrollo de la temática del castillo incorporada en la novela. Espacio representado, en este caso, por la mansión del conde Vladimir Radu, que poco a poco adopta las características del antiguo castillo medieval, en el que cobran vida cada uno de sus elementos, como se muestra en seguida.

En Vlad se narra la historia del abogado Yves Navarro -quien tiene como correlato al personaje Jonathan Harker, de Stoker-, a quien su anciano jefe, dueño de una firma de abogados, el licenciado Eloy Zurinaga -y personaje paralelo al señor Hawkins,

11 "El castillo está estrechamente vinculado con el feudalismo. Su imagen recurrente en el imaginario europeo indica que la época y el sistema feudal, que rigió entre el siglo x y la Revolución Francesa, fue un estrato fundamental de las realidades materiales, sociales y simbólicas de Europa” (Le Goff 69). 
de Stoker- encomienda la tarea de encontrar una residencia en la Ciudad de México para un viejo amigo que ha sido despojado de sus propiedades en la frontera húngaro-rumana. Zurinaga sugiere a Navarro que entre él y su esposa Asunción -quien tiene una agencia de bienes raíces- podrían resolver el problema habitacional de su amigo, el conde Vladimir Radu -el conde Drácula, de Stoker-, quien se dirige a la Ciudad de México para instalar su residencia, acompañado de su hija de diez años, Minea, ${ }^{12}$ y de su mayordomo, Borgo. Dicha empresa se tornará finalmente en una pesadilla para el protagonista y su familia, integrada por su esposa Asunción y su hija Magdalena, de diez años, quienes han sufrido la pérdida de su hijo Didier, de doce años.

Es importante destacar, como bien observa Gutiérrez Mouat, que el motivo del inquilino aparece de manera constante en esta narrativa del autor: "la diversa producción gótica de Fuentes exhibe una notable consistencia estructural definida por el motivo del alojado o inquilino, figura análoga al de una conocida cinta fílmica de Roman Polanski” (6). Al respecto, como ejemplos, el estudioso menciona, en el "Chac Mool", el alojado es el dios maya de la lluvia en forma de estatuilla; en Aura, Felipe Montero; en Una familia lejana, el conde Branly; en Constancia, el actor ruso exiliado; en Vlad, el vampiro, el conde Vladimir Radu, quien busca alojamiento en la Ciudad de México. Esta combinatoria del personaje milenario y el espacio de la mansión que habitará el conde es la que hará posible que cobre vida el mito del vampiro en pleno siglo XxI.

Quien presenta los acontecimientos en la novela es el protagonista, Yves Navarro, lo que implica que estos han concluido y es entonces cuando el personaje se dispone a narrarlos: "Cuando, semanas más tarde, la horrible aventura terminó, recordé que en el primer momento atribuí al puro azar que Dávila anduviese de viaje lunamielero en Europa y Uriarte metido en un embargo judicial

${ }^{12}$ Minhea III era el nombre de una hija del personaje histórico Vlad Draculea, mejor conocido como Vlad «Tepes». 
cualquiera" (Fuentes 11). ${ }^{13}$ Desde el inicio de la novela, el protagonista aclara a sus lectores que todo aquello que ocurrió no fue causa del azar sino algo deliberadamente planeado. Esta idea se acentúa en el recuento de los hechos, elaborado por el narrador, mediante frases que subrayan irónicamente lo premeditado de las situaciones. Por ejemplo, cuando el protagonista refiere el momento en que Zurinaga le encarga la tarea de conseguir una casa para su amigo, señala: "Qué feliz coincidencia -repitió el viejo-. Usted es abogado en mi bufete. Ella tiene una agencia de bienes raíces. Albricias, como se decía antes. Entre los dos, el problema habitacional de mi amigo está resuelto" (21).

En una primera lectura, estos guiños pasan por lo regular inadvertidos para el lector aun cuando se tenga fresco en la memoria el referente de la novela de Stoker y se sepa que todos los pasos están fríamente calculados por el vampiro, desde el principio hasta el fin de la historia. El hecho de que el protagonista de Vlad pueda elaborar el recuento de los horrorosos acontecimientos ocurridos a su familia significa que han concluido y que este ha sobrevivido con su memoria intacta para poder dar cuenta de lo ocurrido. Para ese momento, Yves se sabe víctima de los engaños de su jefe, el licenciado Eloy Zurinaga, quien controlado por Vlad obedece sus órdenes destinadas a preparar el terreno para su llegada a la Ciudad de México. Tarea por la que Zurinaga espera una compensación: la vida eterna que el vampiro le promete. Aunque el protagonista conoce el desenlace de los acontecimientos al momento de narrarlos, su relato presenta la información de manera gradual, tal y como él la recibió y vivió durante su horrible aventura. De esta manera, cuando el protagonista revive lo que le sucedió para contarlo, el lector a su vez "vive" paso a paso los terroríficos sucesos tal y como lo hizo en su momento el personaje Yves Navarro.

13 Carlos Fuentes, Vlad (2010), 1a. reimp., cubierta y viñetas, José Ignacio Galván, México, Alfaguara, 2011. Todas las referencias a la novela provienen de esta edición autónoma del texto y, en adelante, se citará únicamente la página referida en cada caso. 
La encomienda que recibe el protagonista de parte de su jefe consiste en encontrar una casa para su amigo el conde. Dicha empresa transcurre en unas cuantas semanas, aproximadamente un mes, breve lapso en que el protagonista lo pierde todo. Ante esta solicitud, Navarro se dirige a su esposa Asunción para darle las características que debe tener la residencia para el cliente y amigo de su jefe:

-El amigo de Zurinaga quiere una casa aislada, con espacio circundante, fácil de defender contra los intrusos y, óyeme nada más, con una barranca detrás... [...]

-Nada más fácil -sonrió Asunción- [...] Me estás describiendo cualquier número de casas en Bosques de las Lomas.

-Espera -interpuse-. Nuestro cliente pide que desde antes de que tome la casa, se clausuren todas las ventanas [...] Parece que sólo tolera la luz artificial. Un problema de los ojos [...] Además, requiere que se cave un túnel entre su casa y la barranca [...] Que pueda comunicarse sin salir a la calle (29).

Las particularidades del inmueble requerido por Zurinaga para su amigo, el conde, hacen que Asunción describa al cliente como "excéntrico"; esto es, no solo como una figura rara y extravagante sino incluso como alguien que está fuera de los espacios o situaciones centrales, o bien, que se coloca en un centro distinto al habitual y cotidiano. Incluso el mismo Vlad utiliza este calificativo para describir sus hábitos, como sucede durante la primera visita del protagonista a su mansión: "Excuse mis horarios excéntricos [...] Durante la guerra se ve uno obligado a vivir de noche" (35). De esta manera, el conde es inmediatamente identificado como una figura situada en espacios alejados de la centralidad y de lo ordinario y se ubica en lugares aislados y clausurados; en este caso, amurallados y tapiados. Es precisamente en un lugar con estas características donde se le localiza una casa: "Los pasos fueron dados puntualmente. Asunción encontró la casa adecuada en el escarpado barrio de Lomas Altas. Yo preparé los contratos del caso y se los entregué a don Eloy" (33). La frase con la que abre esta cita mantiene el acento en 
las señales, antes referidas, que recuerdan al lector lo premeditado de los acontecimientos aludidos por el protagonista.

Si bien la mansión encontrada para el conde no está en un espacio completamente aislado, pues se ubica en la conglomerada Ciudad de México, el hecho de localizarse en una zona exclusiva de la ciudad, como es la colonia Bosques de las Lomas, la aproxima suficiente a las particularidades de la narrativa gótica -que privilegia los espacios apartados, confinados y de difícil acceso-. A estas particularidades de la mansión se suman los arreglos que el conde Vlad precisa y que terminan transformándola en un espacio desolado y lúgubre. Por ejemplo, manda talar el antiguo bosque de sauces y ahuehuetes de la barranca que tiene detrás hasta quedar convertido en un paisaje de aterradoras estacas listas para empalar a sus víctimas; $\mathrm{y}$-como antes se refirió- ordena construir un túnel que conecte la mansión con la barranca, así como clausurar absolutamente todas las ventanas para que no penetre el más mínimo rayo de sol.

Como se puede observar, se trata de adaptar el nuevo espacio-tiempo al del tiempo natal del personaje histórico. De esta manera, el antiguo castillo del sanguinario personaje, el conde Vlad Tepes, cobra poco a poco vida en la nueva mansión de la escarpada zona de Bosques de las Lomas, en la Ciudad de México, en la cima de una abrupta montaña donde, como señala Jacques Le Goff, el castillo funciona como fortaleza y centro de mando: "En los siglos XI y XII, el desarrollo de los castillos sobre montículos suscitó la construcción de fortalezas que dejarían, en el imaginario europeo, una de las formas espectaculares del castillo fortificado [...] el castillo fue, fundamentalmente, un centro de mando" (Le Goff 70). Habrá que recordar que Vlad Tepes, fue -durante el siglo XV- señor feudal de los Cárpatos y príncipe de Valaquia, territorio donde se ubicaba su antiguo castillo, siempre en constantes guerras y asedios enemigos, características que vienen a determinar las particularidades de la nueva residencia del conde Vladimir Radu en la novela.

La incorporación de la temática del castillo posibilita que poco a poco ese remotísimo pasado histórico cobre vida, sobre todo a partir de diversas narraciones de leyendas centroeuropeas referidas 
en el texto. A esto habría que añadirse el hecho de que la mansión en la que se instala el conde Vladimir Radu presenta, como ya se señaló, cada una de las características del antiguo castillo medieval: con sus fosos o barrancas que circundan la fortaleza, oscuros sótanos o túneles subterráneos, paisajes desolados y lúgubres; espacios, todos estos, que hacen resurgir un tiempo antiguo, el pasado histórico en el que existió el castillo del príncipe de Valaquia, Vlad Tepes; las genealogías e historias de quienes lo habitaron, la atmósfera de tiempos de guerras, etcétera.

El lector puede presenciar cómo resurge, en lo escarpado de la estratégica ubicación de la mansión de Vladimir Radu, el antiguo castillo del señor feudal de los Cárpatos y príncipe de Valaquia, Vlad Tepes; fortaleza antiguamente ubicada en una zona fronteriza, de conflicto, de guerra. En la barranca trasera de la mansión de Bosques de las Lomas, habitada por Vlad, llena de árboles talados y convertidos en estacas, cobran vida las escenas de los miles de empalados, víctimas de la crueldad de Tepes. El túnel con sus ataúdes y murciélagos, los aposentos vacíos, la cocina ensangrentada con restos de animales destazados, las ventanas tapiadas y el suelo cubierto de coladeras por donde brota sangre, no dejan lugar a dudas de que el castillo del conde Vlad Tepes, esa antigua "fortaleza habitada", ha resurgido en la mansión de Bosques de las Lomas, en la Ciudad d México.

Son varias las historias narradas por los personajes que posibilitan que los antiguos relatos cobren vida en el espacio de la mansión y sus alrededores. Por ejemplo, en el manuscrito elaborado por Zurinaga para Yves Navarro -quien a su vez intercala fragmentos de este en su propio relato-, el personaje afirma contar "los secretos -parciales-" sobre el conde. Entre estos refiere el origen de Vlad: "En el año del Señor 1448 ascendió al poder de Valaquia Vlad Tepes [...] con la encomienda cristiana de combatir al Turco, en cuyas manos cayó Vlad, quien aprendió velozmente las lecciones del sultán Murad II: sólo la fuerza sostiene al poder y el poder exige la fuerza de la crueldad" (82). La historia narrada en el manuscrito detalla las cruentas ejecuciones masivas de Vlad por medio del empalamiento y cobra entonces sentido "el jardín" del conde: esa 
barranca con su bosque de sauces y ahuehuetes talados y convertidos en estacas.

Estas historias hacen revivir al monstruo que habita la mansión, quien para ese momento se ha despojado del grotesco disfraz con el que se presenta ante el protagonista al inicio de la novela -compuesto por una peluca y bigote postizos de color rojizo- y aparece entonces sin máscara alguna y con el mayor cinismo confiesa ante Navarro -quien encuentra en la mansión de Vlad a su hija y a su mujer desaparecidas, la primera jugando en la barranca y, la segunda, en un ataúd, vampirizada- que quien realmente le interesa no es su esposa sino su hija Magdalena:

No me interesa su esposa, Navarro. Me interesa su hija. Es la compañera ideal para Minea. Son casi gemelas. Viera usted la cantidad de fotografías que hube de escudriñar en las largas noches de mi arruinado castillo en la Valaquia hasta encontrar a la niña más parecida a la mía. ¡Y en México, una ciudad de veinte millones de nuevas víctimas, como las llamaría usted! [...] ¡Veinte millones de sabrosas morongas! (95).

Ni siquiera el cinismo expuesto por el vampiro logra que el protagonista pierda el control sobre sus buenos modales y hasta el último momento Navarro se conduce con propiedad ante el conde Vlad, pues se trata de un individuo ejemplar, de buenos modales e incorruptible hasta el último momento. Es importante el hecho de que la novela mantenga el acento es estas cualidades del protagonista porque, de esta manera, el golpe final acertado por el vampiro será fulminante no solo para el protagonista sino para las expectativas del lector.

El legajo de Zurinaga alude también a la obsesión y el deseo con el que Vlad escuchaba las leyendas de su tierra, particularmente sobre los diferentes tipos de vampiros, que Zurinaga se toma la molestia de referir uno por uno y con lujo de detalle, completando con estas criaturas la atmósfera de horror: los nosferatu "apenas enterrados [...] despiertan y abandonan su tumba para jamás regresar a ella, recorriendo la noche en forma de perros oscuros, es- 
carabajos o mariposas. Envenenados de celo, gustan de aparecerse en recámaras nupciales y volver estériles e impotentes a los recién casados" (85); los lúgosi son "cadáveres vivientes, librados a las orgías necrofílicas al borde de las tumbas y delatados por sus patas de pollo[, los strigoli de Braila tienen los] ojos perpetuamente abiertos dentro de sus tumbas[, los varcolaci de] rostros pálidos y epidermis reseca que caen en sueño profundo para imaginar que ascienden a la luna y la devoran: son niños que murieron sin bautizo" (85) y, finalmente, los moroni, "capaces de metamorfosis en gato, mastines, insectos o arañas" (84).

Estas historias sobre vampiros, referidas por Zurinaga, tienen su origen en antiguas leyendas rumanas sobre las que Édouard Brasey refiere: "los vampiros, o nosferatus, se clasifican en drakuls, vampiros diabólicos, vercolacs, ectoplasmas 'comedores de luna', pryccolitchs o strigoi, personas vivas dotadas del poder de metamorfosearse en animales, y moroni, niños rechazados por sus padres que prosiguen su vida en forma de espíritus larvarios o de muertos vivientes" (Brasey 93). En esta clasificación referida por Brasey, el personaje histórico de Vlad III Draculea sería el origen de un tipo de vampiros: los "drakuls, vampiros diabólicos".

Esta serie de leyendas, rememoradas por Zurinaga en su manuscrito, pueblan los rincones de la mansión del conde, pues a los moroni pertenecen los niños vampiro como Minea, la hija de Vlad. Con relación al origen de la pequeña, el manuscrito refiere:

Capturado al fin en medio de su última batalla [...] Vlad el Empalador fue condenado a ser enterrado vivo [...] pasaba encadenado, de pie, en un carretón que lo conducía rumbo al camposanto. Nadie quería recibir su última mirada. Sólo un ser le daba la cara [...] era una niña apenas, de no más de diez años de edad. Miraba al Empalador con una mezcla impresionante de insolencia e inocencia, de ternura y rencor, de promesa y desesperanza (85-86).

Posteriormente, el propio Vlad narra su historia y la de su hija Minea al protagonista, relato que permite completar la versión re- 
ferida por Zurinaga. Vlad cuenta cómo el nuncio papal, Gabriel Rangone, lo acusó de empalar a cien mil personas y cómo el mismo Papa lo condena a permanecer enterrado en vida en una cavernosa tumba anónima, donde se alimenta de raíces, tierra, ratas, murciélagos, serpientes y arañas hasta que:

los pobladores de Valaquia oyeron el consejo ancestral. Que una niña desnuda montada a caballo recorra todos los cementerios de la región a galope, y allí donde se detenga el caballo estará escondido Vlad y allí mismo le hundiremos una estaca en el pecho [...] Una noche al fin oí el galope funesto [...] El galope se alejó. Una hora más tarde, la niña desnuda regresó [...] abrió las compuertas de fierro [...] "Me llamo Minea, [...] le encajé las espuelas al caballo cuando se iba a detener sobre tu escondite. Así supe que estabas enterrado aquí. Ahora sal. He venido a rescatarte [...] Cuando empezó la cacería contra ti, me ofrecí candorosamente [...] Vengo a ofrecerte un trato. Sal de esta cárcel y únete a nosotros. Te ofrezco la vida eterna [...]" La niña Minea se lanzó sobre mi cuello y allí me enterró los dientes [...] Ella me arrancó los ojos, se los chupo como se lo chupa todo, para que mis ojos no expresaran otra necesidad que la sangre, ni otra simpatía que la noche... (97-98).

El consejo ancestral al que refiere Vlad alude precisamente a las creencias de la población, a sus tradiciones y supersticiones rememoradas, en esta ocasión, por el vampiro. El origen de Minea, aludido en la novela, coincide con el que atribuyen las leyendas de Siberia a los hijos de vampiros llamados dhampirs, estos "tenían el poder de descubrir los lugares donde se escondían los muertos vivientes, incluso de día” (Brasey 94). Aunque estas historias también señalan que "se recurría a un muchachito montado en un semental blanco que no hubiera conocido yegua. El caballo y su jinete recorrían el cementerio, entre las tumbas, hasta que la montura hacía una espantada. Entonces se cavaba la tierra y se exhumaba el ataúd, que la mayoría de las veces no contenía huesos, sino un vampiro atiborra- 
do de sangre" (94). Esta serie de leyendas sobre vampiros, introducidas en la novela, no solo ayudan a configurar al conde Vlad y a su hija Minea, principales habitantes de la mansión, sino que permiten completar la configuración y el resurgimiento del tiempo-espacio del castillo mediante la historia de estos personajes, al actualizarlas, revivirlas y hacerlas presentes en pleno siglo XXI.

Como se observa, son muchas y muy diversas las referencias provenientes de la cultura popular incorporadas a lo largo del texto, las cuales sirven a un mismo propósito en la novela gótica: que esas historias y creencias rememoradas del pasado cobren vida en el espacio donde acontecen las acciones en el curso de la historia y sobre todo en la imaginación de los lectores. Federico Patán apunta otros elementos importantes de este género literario que viene al caso mencionar:

la literatura gótica es transgresora de las buenas costumbres que las estructuras sociales prefieren como reflejo de sí mismas [...] La parte oculta de nosotros y de nuestro medio brota a la superficie en la literatura gótica y nos hace conscientes de su existencia $[. .$.$] asegura, tal narrativa, que justo el medio$ social crea esa parte oscura. Y entonces viene la paradoja: presentándonos mediante monstruos o personajes calamitosos esa otra parte de nosotros (124).

Este tipo de transgresiones se observan claramente en Vlad, por ejemplo, mediante la destrucción, a manos del vampiro, de la familia y de los valores ético-morales del protagonista, de sus dogmas religiosos, del amor y de la pasión conyugal cotidianos de la pareja, principalmente. $\mathrm{Al}$ respecto, Del Toro afirma que, en este punto,

empatiza el vampiro literario de Fuentes con el primer vampiro en la historia de la literatura de habla inglesa, que es el vampiro de Polidori ${ }^{14}[\ldots]$ en este vampiro, igual que en Drá-

${ }^{14}$ Se refiere al famoso relato de John William Polidori, The Vampyre (1816), cuya escritura del texto se alude siempre a partir de la conocida anécdota en la 
cula, la misión del personaje [...] no es solo beber la sangre de los que lo rodean sino destruir el alma y la esencia de los que lo rodean e invade la familia del personaje narrador y la destruye desde dentro, igual que el Vlad, de Fuentes, igual que el Drácula, de Stoker. ${ }^{15}$

Como parte de la destrucción familiar, el conde se mofa del amor y la pasión conyugal cotidiana que se profesan el protagonista, Yves Navarro, y su esposa Asunción: "Francamente, no veo qué le encuentra usted de maravillosa. Elle est une femme de ménage!" (100); afirma Vlad, dirigiéndose al protagonista, para opinar sobre su esposa.

La transgresión del dogma católico se presenta con la consumación del rapto de la familia de Yves Navarro (su esposa e hija) por parte del vampiro, que ocurre exactamente el 15 de agosto, día de la Virgen de la Asunción y santo de la esposa del protagonista. En esta fecha, la Iglesia católica celebra el ascenso de la Virgen al cielo, en cuerpo y alma. Asunción, la esposa del protagonista, al contrario, ese mismo día se une en cuerpo y alma a un ser de la oscuridad y desciende al túnel de la mansión del conde, donde ocupa uno de los sarcófagos. Esto ocurre precisamente en el mes de agosto, durante la estación de otoño, que representa un periodo de la vida humana en el que ésta declina de su plenitud a la vejez. Sin embargo, en el caso de Vlad y contra toda ley de la naturaleza, este rejuvenece después de vampirizar a Asunción y a su hija Minea, como observa el protagonista: "Por un instante no lo reconocí. Se envolvía en una capa dragona y la cabellera le caía sobre los hombros, negra y

que, reunidos en la Villa Diodati -una mansión ubicada en Cologny, Suiza, cerca del lago Ginebra- se encontraban Mary y Percy Shelley, Lord Byron, Claire Clairmont, Matthew Lewis y Polidori, quienes se dan a la tarea de escribir, una noche de tormenta, una historia de terror. Los únicos que cumplieron con esta tarea fueron Mary Shelley y Polidori; la primera escribió el argumento de su obra Frankenstein y, el segundo, su relato El Vampiro.

${ }^{15}$ Estos comentarios son expuestos por Del Toro en https://www.youtube. com/watch?v=a7o6Ds4akXY (consultado el 4 de septiembre de 2017). 
lustrosa. No era una peluca más. Era el cabello de la juventud, renacido, brillante, espeso" (94).

Al conde Vlad no le basta con destruir a la familia del protagonista, sino que va tras lo que queda de este, su ética inquebrantable: "únase a nosotros, Navarro. Sea parte de mi tribu errante. Mire lo que le ofrezco, a pesar de su insobornable orgullo: quédese con su mujer y su hija, aquí, eternamente" (106). Ante la negativa de Navarro, al final de la novela, Vlad juega su última carta, vinculada con el elemento autobiográfico que destaca Molina: “¿No le gustaría que su hijo resucitara? ¿Eso también lo despreciaría usted? No me mire de esa manera, Navarro. No acostumbro bromear en asuntos de vida y muerte. Mire, allí está su coche estacionado. Mire bien y decídase pronto" (106-107).

El horror y la alegría asaltan al protagonista en las últimas líneas de la novela:

Me fui acercando al coche estacionado.

Algo se movía dentro del auto.

Una figura borrosa.

Cuando al cabo la distinguí, grité de horror y júbilo mezclados.

Me llevé las manos a los ojos, oculté mi propia mirada y sólo pude murmurar:

-No, no, no... (111).

El reencuentro con el hijo muerto, Didier, es la carta escondida bajo la capa dragona del vampiro, con la que da un golpe mortal al protagonista. Finalmente, el lector puede deducir que Navarro no logra librarse de Vlad porque, aun después de la aterradora aventura, este puede recordar todo lo acontecido, pues es él quien lo narra. Y este sólo olvidaría todo lo ocurrido en caso de no unirse a la tribu de Vlad, en caso de no aceptar el trato propuesto por el monstruo: "Usted olvidará este lugar y este día. Usted nunca estuvo en esta casa. Nunca" (108), afirma el vampiro. De esta manera, la narración que Navarro elabora de los acontecimientos ocurridos es hecha, con toda seguridad, desde la lúgubre mansión del vampiro en la que habita el protagonista, unido a la tribu errante de Vlad. 
Finalmente, no se puede dejar de advertir que muchos de los autores del género de novela gótica han referido en sus textos que la evolución de éste "responde a diferentes circunstancias $[. .$.$] a un$ desencanto o reacción ante cuestiones políticas como puede ser el fracaso de los ideales promulgados por la Revolución Francesa", por ejemplo (Estévez 82). El hecho de que Fuentes decida publicar el relato de "Vlad" como texto autónomo, exactamente el año de la celebración del centenario de la Revolución Mexicana y del bicentenario de la Independencia, resulta, por lo menos, sugerente. La novela no solo plantea, como antes se vio, la transgresión de las buenas costumbres -la destrucción de la familia, el amor y la pasión conyugales, los dogmas católicos, los valores éticos- sino que, a la luz de la celebración de dichas revoluciones -que rememoran el triunfo de una liberación ante el sometimiento a un poder superior (feudal, monárquico, dictatorial, etc.)-, la novela se revela como una burla irónica de estos festejos. Pues la historia narrada en Vlad presenta finalmente el triunfo del monstruo, esa especie de señor feudal vampirizado que es el conde Vlad y que representa las fuerzas oscuras que emergen del pasado milenario para imponer su omnipotencia. Es Vlad quien destruye la familia y la vida del protagonista "insobornable", se burla de todo lo que ama y lo apasiona, de sus creencias y valores. La imagen del hombre que se revela en esta novela neogótica de Fuentes es la de un ser completamente dominado, sometido por esas fuerzas oscuras del pasado, que lo arrastran hasta su desgracia sin la más mínima posibilidad de salvación.

\section{Obras consultadas}

Bajtín, Mijaíl. "Las formas del tiempo y del cronotopo en la novela". Teoría y estética de la novela. Trabajos de investigación, traducción Helena S. Krukova y Vicente Cazcarra. Madrid, Taurus, 1989, pp. 237-409.

Brasey, Édouard. Brujas y demonios. El universo feérico v, traducción Esteve Serra, Barcelona, Morgana, 2001. 
Del Toro, Guillermo. Presentación de la novela Vlad en la Feria del libro de Guadalajara 2010. https://www.youtube.com/watch?$\mathrm{v}=\mathrm{a} 7 \mathrm{o} 6 \mathrm{Ds} 4 \mathrm{akXY}$.

Estévez Saá, Margarita. "Literatura gótica en lengua inglesa: avatares de un 'género' popular". Garoza. Revista de la Sociedad Española de Estudios Literarios de Cultura Popular, núm. 3, 2003, pp. 67-88.

Fuentes, Carlos. Vlad, reimpresión, cubierta y viñetas, José Ignacio Galván. Alfaguara, 2011.

---. "Vlad". Inquieta compañia, 3a reimp. Alfaguara, 2013, pp. 209-283.

---. Presentación de un fragmento de la novela Vlad. https://www. youtube.com/watch?v=D2-v9niw0Ko.

Gutiérrez Mouat, Ricardo. "La retórica de la monstruosidad en la narrativa latinoamericana contemporánea: Un panorama crítico". Hispamérica, año 34, núm. 101, 2005, pp. 3-13.

Le Goff, Jacques. Héroes, maravillas y leyendas de la Edad Media, traducción José Miguel González Marcen. Paidós, 2010.

Märtin, Ralf-Peter. Drácula. Vlad Tepes, el Empalador, y sus antepasados, traducción Gustavo Dessal, Tusquets, 2009.

Martínez Díaz, Alicia Nila. "Contázar, Fuentes y Molina en los confines de lo humano: tres cuentos de vampiros". Anales de Literatura Hispanoamericana, vol. 45, 2016, pp. 429-448.

Molina, Mauricio. "Escrito con sangre. De ángeles, fantasmas y vampiros. Notas sobre Inquieta compañia de Carlos Fuentes". Revista de la Universidad de México, núm. 3, 2004, pp. 31-36.

Patán, Federico. "Una rosa para Amelia (Cuentos góticos mexicanos)". Cuento y figura (La ficción en México), edición, prólogo y notas de Alfredo Pavón. Universidad Autónoma de Tlaxcala, 1999, pp. 121-134.

Quirarte, Vicente. "Presentación". Bram Stoker, Drácula, traducción Manuel Núñez Nava, ilustración Manuel Marín. Consejo Nacional para la Cultura y las Artes, 2002, pp. 7-11.

Roas, David. "Breve historia de la literatura fantástica (siglo xviii y xix)". La recepción de la literatura fantástica en la España del siglo XIX. Tesis doctoral, Universidad Autónoma de Barcelona, 2000, pp. 65-79. 